\title{
THE
}

\section{Organic Pollutants and Ocean Fronts Across the Atlantic Ocean: A Review}

Rainer Lohmann

University of Rhode Island, rlohmann@uri.edu

Igor M. Belkin

University of Rhode Island, igormbelkin@gmail.com

Follow this and additional works at: https://digitalcommons.uri.edu/gsofacpubs

The University of Rhode Island Faculty have made this article openly available.

Please let us know how Open Access to this research benefits you.

This is a pre-publication author manuscript of the final, published article.

Terms of Use

This article is made available under the terms and conditions applicable towards Open Access Policy Articles, as set forth in our Terms of Use.

\section{Citation/Publisher Attribution}

Lohmann, Rainer; Belkin, Igor M. (2014). "Organic pollutants and ocean fronts across the Atlantic Ocean: A review." Progress in Oceanography. 128: 172-184.

Available at: https://doi.org/10.1016/j.pocean.2014.08.013

This Article is brought to you for free and open access by the Graduate School of Oceanography at DigitalCommons@URI. It has been accepted for inclusion in Graduate School of Oceanography Faculty Publications by an authorized administrator of DigitalCommons@URI. For more information, please contact digitalcommons-group@uri.edu. 


\section{Organic Pollutants and Ocean Fronts}

\section{Across the Atlantic Ocean: A Review}

\section{Rainer Lohmann* and Igor Belkin}

Graduate School of Oceanography, University of Rhode Island, 215 South Ferry Road, Narragansett, 02882 Rhode Island, USA

* Corresponding author: Tel: 001-401-874-6612, Fax: 001-401-874-6811, E-mail: lohmann@gso.uri.edu

Abstract. Little is known about the effect of ocean fronts on pollutants dynamics, particularly organic pollutants. Since fronts are associated with convergent currents and productive fishing grounds, any possible convergence of pollutants at fronts would raise concerns. The focus here is on relatively persistent organic pollutants, POPs, as nonpersistent organic pollutants are rarely found in the open ocean. Results from recent cruises in the Atlantic Ocean are examined for POPs distribution across ocean fronts in (i) the Canary Current; (ii) the Gulf Stream; and (iii) the Amazon and Rio de la Plata Plumes. Few studies achieved a spatial resolution of 10 to $20 \mathrm{~km}$, while most had 100 to $300 \mathrm{~km}$ between adjacent stations. The majority of the well-resolved studies measured perfluorinated compounds (PFCs), which seem particularly well suited for frontal resolution. In the NE Atlantic, concentrations of PFCs sharply decreased between SW Europe and NW Africa upon crossing the Canary Current Front at $24^{\circ}-27^{\circ} \mathrm{N}$. In the Western Atlantic, the PFC concentrations sharply increased upon entering the Amazon

22 River Plume and Rio de la Plata Plume. In the NW Atlantic, concentrations of several pollutants such as polycyclic aromatic hydrocarbons are very high in Rhode Island Sound, decreasing to below detection limit in the open ocean. The more persistent and already 
25 phased-out polychlorinated biphenyls (PCBs) displayed elevated concentrations in the

26 Gulf Stream and Rhode Island Sound, thereby highlighting the importance of ocean

27 fronts, along-front currents, and cross-frontal transport for the dispersal of PCBs.

28 Keywords: fronts, organic pollutants, PFC, PCB, river plumes

29 Regional Index terms: North Atlantic Ocean; Gulf Stream; Azores Current; Canary

30 Current; Rhode Island Sound; South Atlantic Ocean; Rio de la Plata; Amazon River.

31

32 FOOTNOTE:

33 POPs: persistent organic pollutants; PCBs: polychlorinated biphenyls; PFCs: perfluorinated compounds; PAHs:

34 polycyclic aromatic hydrocarbons; PFOA: perfluorooctanoic acid; PFOS: perfluorooctane sulfonate; HCHs:

35 hexachlorocyclohexanes; HCB: hexachlorobenzene; PBDEs: polybrominated diphenylethers 


\section{Introduction: Fronts and organic pollutants}

40 Front is a narrow band of enhanced gradients of physical, chemical and biological

41 properties (temperature, salinity, nutrients etc.) that separates distinctly different water

42 bodies (Belkin, 2002). Cross-frontal ranges (steps) of temperature and salinity of up to

$4310^{\circ} \mathrm{C}$ and 3 psu respectively are routinely observed, though generally these steps are

44 much smaller, typically $2-$ to- $3^{\circ} \mathrm{C}$ and $0.5-1.0 \mathrm{psu}$. Fronts are typically associated with

45 enhanced productivity at all trophic levels, including fishery grounds; yet a low-

46 productivity front was observed (Caldeira et al., 2001). Fronts are formed by numerous

47 processes, including tides and tidal mixing, winds, solar heating, current convergence,

48 upwelling/downwelling, advection, convection, precipitation/evaporation, sea ice

49 formation etc. (Belkin, 2002).

$50 \quad$ Fronts and frontal processes play important roles in spatial distribution and temporal

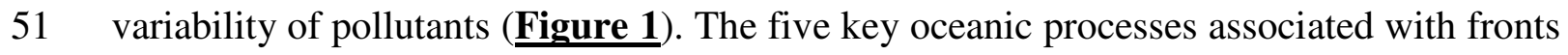

52 (yellow arrows in Figure 1) are (1) particle sinking, (2) downwelling, (3) turbulent

53 mixing, (4) convection, and (5) upwelling. Many fronts are convergent (Belkin et al.,

54 2009), hence associated with downwelling, which enhances particle sinking. Some fronts

55 feature downwelling on one side and upwelling on the opposite side, thus exerting

56 opposite effects on particle sinking. Turbulent mixing at fronts can be enhanced by up to

57 two orders of magnitude vs. ambient ocean (D'Asaro et al., 2011). Downwelling and

58 upwelling are two components of ocean convection, hence water mass formation and

59 conversion. Cascading along continental slope (dark blue arrow in Figure 1) is often

60 associated with shelf-slope fronts located over the shelf break. The three key

61 atmospheric processes associated with fronts (light blue arrows in Figure 1) are (1) dry 
62 deposition, (2) wet deposition, and (3) volatilization. Major fronts associated with the

63 western boundary currents - Gulf Stream, Kuroshio etc. - and with the Antarctic

64 Circumpolar Current can impact the entire lower troposphere up to $1 \mathrm{~km}$ above sea

65 surface (Small et al., 2008), thereby directly affecting dry deposition and wet deposition

66 rates. Such fronts also modulate near-surface wind stress (Small et al., 2008), hence

67 volatilization rates. In shallow seas, fronts extend vertically throughout the entire water

68 column and interact with bottom currents (dark blue arrow in Figure 1). Even in the deep

69 ocean, fronts associated with western boundary currents can generate strong bottom

70 currents ("benthic storms") with a speed of $>30 \mathrm{~cm} / \mathrm{s}$, leaving ripple marks at depths over

$714,000 \mathrm{~m}$ (Hollister and McCave, 1984).

72 Fronts separate water masses with different concentrations of pollutants. Most major

73 fronts are associated with along-front geostrophic currents that transport pollutants across

74 a wide variety of scales. Conservative pollutants can be carried by along-front currents

75 across oceans and around the globe. Rate of turbulent energy dissipation in major frontal

76 zones (Kuroshio, Gulf Stream, Antarctic Circumpolar Current etc.) is "enhanced by one

77 to two orders of magnitude, suggesting that the front, rather than the atmospheric forcing,

78 supplied the energy for the turbulence" (D'Asaro et al., 2011), thereby greatly enhancing

79 dissipation of pollutants in these frontal zones. Surface convergence and downwelling at

80 fronts may result in reduction of surface concentrations of pollutants; this effect was

81 dubbed "self-cleaning" (of fronts) by Sherstyankin (1999). When upwelling develops

82 along one side of a front, it brings relatively pristine deep waters to the surface. Deep

83 convection associated with some fronts (e.g., formation of the Subantarctic Mode Water

84 north of the Subantarctic Front) tends to pump surface contaminants to intermediate and 
85 deep layers. Frontal eddies and intra-thermocline lenses effectuate cross-frontal transfer

86 of pollutants between water masses separated by fronts, acting on the synoptic, meso- and

87 small scales, while frontal interleaving, double diffusion, and turbulent mixing effectuate

88 cross-frontal flux of pollutants on the fine scale. Some physical processes are endemic to

89 fronts, e.g., interleaving (especially active across density-compensated fronts) and

90 cabbeling (densification and sinking of a mixture of two water parcels of the same

91 density but different temperature and salinity). Some chemical processes - even if not

92 truly endemic to fronts - may intensify in frontal zones owing to either high gradients of

93 properties or vigorous ocean-atmosphere-ice interaction or elevated biological activity or

94 all of the above - and more. For example, estuarine fronts act as "marginal filters"

95 (Lisitsyn, 1995) by trapping fine river sediments that carry contaminants (Macdonald et

96 al., 2005); the main processes acting at these marginal filters are "flocculation and

97 coagulation of dissolved (colloidal) and suspended matter" (Lisitsyn, 1995).

98 Little is known about the effect of ocean fronts on organic pollutants, but any

99 possible convergence of pollutants in productive fishing grounds associated with fronts

100 would be a cause for concern, especially given the effect of biomagnification since many

101 frontal species are top predators, e.g., tuna and billfish. The pioneering work by Tanabe

102 et al. (1991) in the Seto Inland Sea (Japan) has demonstrated that organic pollutants,

103 particularly those bound to particles, can be enriched in fronts. Since organic pollutants

104 are not routinely investigated across ocean fronts, it is appropriate to first outline the

105 possible effects of fronts on organic pollutant dynamics. As most fronts are associated

106 with surface convergence toward the front, we expect a truly dissolved compound to have

107 a frontal concentration that changes monotonously across the front (Figure 2, top) in the 
108 same fashion as temperature and salinity. Yet at the same convergence, floating particles

109 or flotsam, e.g., phytoplankton or floating plastic debris, would have a maximum

110 concentration at the surface, within the front, while the water masses separated by the

111 front would sink owing to downwelling circulation along the frontal interface (Figure 2,

112 bottom). The same logic applies to pollutants concentrated in the sea surface microlayer

113 (Wurl and Obbard, 2004). The importance of plastic particles as vectors of organic

114 pollutants is currently under debate (Teuten et al., 2007; Gouin et al., 2011), while there

115 is agreement that many organic pollutants strongly sorb to man-made polymers present in

116 the ocean. Thus, dissolved versus particle-bound pollutants are expected to have different

117 cross-frontal distribution patterns at convergent fronts.

118 Not all fronts are convergent. Some fronts feature downwelling on one side and 119 upwelling on another. Typically, the upwelled deep water is less polluted than surface 120 water, thereby creating a strong contrast in dissolved organic pollutant concentrations 121 across surface manifestations of upwelling fronts. Fronts with a complex multi-layer 122 vertical structure have been reported. For example, Houghton (2002) performed a dye 123 experiment in the shelf-break front (SBF) on Georges Bank. At the front, surface 124 convergence caused downwelling while bottom convergence caused upwelling. The 125 surface-intensified downwelling and bottom-intensified upwelling converged at mid126 depth, resulting in mid-depth divergence or a returning mid-depth flow on both sides of 127 the front (Houghton, 2002).

128 Beyond these purely physical mixing processes, there is also evidence for the 129 enhancement of phytoplankton at fronts (Belkin and O'Reilly, 2009). For example, Ryan 130 et al. (1999a, 1999b) observed a strong seasonal chlorophyll enhancement at the shelf 
131 break of the Mid-Atlantic Bight in the spring that lasted into late June. Such massive

132 chlorophyll blooms along physical fronts must have profound effects on distribution of

133 organic pollutants. Major fronts are associated with elevated primary production and

134 enhanced vertical flux of carbon-rich particles that lead to the increased vertical export of

135 organic contaminants on sinking particles from the surface layer to intermediate and deep

136 waters (Dachs et al., 2002; Macdonald et al., 2005).

137 In terms of organic pollutants, we are focusing on relatively persistent organic

138 pollutants, POPs, as non-persistent organic pollutants are rarely found in the open oceans.

139 We can divide these persistent pollutants in two categories: (1) those that are

140 predominantly dissolved, with little tendency to bioaccumulate or sorb significantly; and

141 (2) organic pollutants that bioaccumulate and sorb to either organic matter such as

142 phytoplankton or floating particles such as plastic debris (Rios et al., 2007) (㺼able 1).

143 Whether a contaminant is predominantly dissolved or bound to organic matter (particles,

144 but also to colloidal material and dissolved organic matter, DOM) depends primarily on

145 the compound's physico-chemical properties (Schwarzenbach et al., 2003). The dissolved

146 vs. sorbed dichotomy is also affected by temperature, salinity, the abundance of organic

147 matter and particles in the water. Lastly, the chemical make-up of the particles also

148 affects the pollutant's propensity to sorb. This holds true both for natural particles and

149 floating synthetic polymers. The disposition of compounds to sorb to organic matter is

150 often estimated by relying on a proxy, such as the compound's partitioning constant

151 between octanol and water, $\mathrm{K}_{\mathrm{ow}}$, (Schwarzenbach et al., 2003). Compounds with low $\mathrm{K}_{\mathrm{ow}}$

152 values prefer to stay dissolved, while those with high $\mathrm{K}_{\mathrm{ow}}$ values $\left(>10^{4}\right)$ tend to bind to

153 organic particles. The sorption of organic compounds to DOC is more complex, but most 
154 studies have focused on DOC isolated from freshwater and sediments (Burkhard, 2000).

155 In a study with coastal DOC, Friedman et al. (2011) suggested that it might sorb PCBs

156 much more strongly than freshwater DOC.

157 Examples of predominantly dissolved POPs include the perfluorinated acids and 158 sulfonates, such as perfluorooctanoic acid (PFOA), perfluorooctane sulfonate (PFOS) and 159 its salts, but also low molecular weight pesticides (hexachlorocyclohexanes, HCHs), 160 chlorinated biphenyls with few chlorines and hexachlorobenzene (HCB). In contrast, the 161 higher molecular weight polychlorinated biphenyls (PCBs) with four or more chlorines, 162 but also polybrominated diphenylethers (PBDEs), strongly bind to organic matter in the 163 water column. A compound that is completely persistent, fully dissolved, and does 164 neither interact with particles nor volatilizes constitutes a perfect tracer for water masses. 165 Recently, Yamashita et al. $(2005,2008)$ proposed to make use of PFOS and PFOA as 166 water tracers, as they are persistent, dissolved and display little tendency to bind to 167 organic matter. The compounds mentioned above have all been targeted by the 168 Stockholm Convention on Persistent Organic Pollutants, which means they have shown 169 to be persistent, bioaccumulate (i.e., enrich up the food chain), prone to long-range 170 transport, and elicit adverse effects. The earliest group of POPs was also known as the 171 'dirty dozen', consisting of PCBs, DDT, dioxins and furans, HCB and other 172 organochlorine pesticides [http://www.chem.unep.ch/gpa trial/01what.htm].

173 Ocean currents were thought to contribute to the long-range transport of POPs, as 174 evidenced by the 'global fractionation' theory developed by Wania and Mackay (1993, 175 1996). Yet the observational programs focused on the global fate of POPs were biased 176 towards atmospheric vs. oceanic transport (Bidleman et al., 1995; Jantunen and Bidleman, 
177 1996), mostly due to logistical and technical constraints of measuring POPs in the water.

178 Ship-based measurements are further complicated by the problem of sampling sufficient

179 volumes of water to overcome detection limits and alleviate contamination concerns on-

180 board ship (Lohmann et al., 2004).

181 In the Arctic Ocean, the importance of currents as pollutant pathways has been

182 recognized, particularly for POP transport. A good example is the fate of two contrasting

183 isomers of hexachlorocyclohexanes (HCHs). While $\alpha-\mathrm{HCH}$ is mostly transported via the

184 atmosphere, the more water-soluble and less volatile $\beta$-HCH (i.e., with a smaller Henry's

185 Law Constant) is thought to be mostly transported via the ocean (Li et al., 2002; Sahsuvar

186 et al., 2003; Pucko et al., 2013). Mass-balance model results for $\alpha-\mathrm{HCH}$ in the Arctic

187 Ocean imply that ocean transport has become the dominant clearance mechanism for $\alpha$ -

$188 \mathrm{HCH}$ in the Arctic Ocean (Li et al., 2004), although microbial degradation dominated $\alpha$ -

189 HCH decrease in the Western Arctic Ocean (Pucko et al., 2013).

190 Similarly, the more recent concerns about the presence of perfluorinated compounds

191 PFOS and PFOA in the Arctic Ocean have pitched their atmospheric transport and

192 oxidation of precursors against their transport with ocean currents (Armitage et al., 2006;

193 Armitage et al., 2009a, 2009b). Overall, the importance of ocean currents as a transport

194 vector for certain POPs has been recognized, but the explicit role of individual fronts in 195 organic pollutant dynamics and distribution has not been investigated in detail.

\section{2. Data Sources}

198 We surveyed the literature for case studies measuring organic pollutants in the 199 Oceans. While plenty of studies have reported organic pollutants in coastal areas and the 
200 Baltic, Mediterranean and other marginal seas, this article focuses on measurements in

201 the open ocean. Relatively few such studies are available for the open ocean for legacy

202 compounds, such as PCBs, PCDD/Fs and OCPs (ㅁaㄹ 2). For classical POPs that are

203 present at around $1 \mathrm{pg} / \mathrm{L}$, such as PCBs (Gioia et al., 2008b), polychlorinated dioxins and

204 furans (Nizzetto et al., 2010), polybrominated diphenylethers or PBDEs (Xie et al.,

205 2011a) and many legacy pesticides (e.g., DDTs) (Lohmann et al., 2009), sampling

206 volumes of around 1,000 L need to be collected to routinely overcome detection limits.

207 This equates to sampling times of around 24 hours, making front resolution in the ocean

208 difficult. As an approximation of frontal resolution, we included an estimation of the

209 typical distance between two consecutive sampling points ( $\underline{\text { Table 2 }}$ ). Only few studies

210 achieved a spatial resolution of $10-20 \mathrm{~km}$, while most had 100 to $300 \mathrm{~km}$ between

211 adjacent stations. Studies with such coarse resolution make the detection of fronts

212 difficult. The high cost of trace-level analysis also prevented continuous water sampling

213 on ocean transects for many years. In the Arctic Ocean, the much higher concentrations

214 of HCHs and HCB enabled their detection in just tens of liters (Jantunen and Bidleman,

215 1996). The recent focus on emerging polar POPs, such as perfluorinated compounds,

216 PFCs (Giesy and Kannan, 2002), went hand-in-hand with the technological advances in

217 life sciences and liquid chromatography-based detection systems, enabling the detection

218 of various PFCs in just one liter of seawater (Yamashita et al. 2005, 2008). For the

219 following discussion, we chose several recent studies that achieved high spatial resolution

220 of POPs concentrations across the Atlantic Ocean.

\section{3. Data Quality}


223 Data quality is of paramount importance when using organic tracer trends across the

224 Oceans. There are numerous challenges to trace-level analysis of organic pollutants in the

225 ocean, which fall into the categories of accuracy and precision of results. Accuracy

226 ('trueness') describes how correct the stated concentration is relative to the 'true' value

227 (if it was known). Laboratories demonstrate the validity of their methods by including

228 standard reference materials (which come with certified concentration ranges) in their

229 analytical runs. Participation in round-robin studies is another way of demonstrating

230 accuracy of results. A major concern regarding shipboard measurements is the

231 contamination of samples during sampling or processing of samples on-board, which

232 would lead to deviations from accurate results. The inclusion of laboratory and field

233 blanks is a necessary, but not sufficient, quality control step in achieving accurate results.

234 Precision deals with the ability of a laboratory to demonstrate reproducible results. For

235 the scope of this paper, samples need not be accurate, but need to be precise in their

236 results to detect the influence of fronts on the distribution of tracers. Precision can be

237 demonstrated through repeat analysis of the same sample, having multiple samples taken

238 at the same time or, at the very least, through repeat injections of the same extract.

239 Typical results of repeat analysis are in the tens of percent, which means that a change in

240 POP concentration of a factor of 2 safely identifies variability outside of analytical

241 uncertainty. As an example, coefficients of variation for triplicate analyses by the same

242 laboratory ('precision') were $14 \%$ to $20 \%$ for PFOA and PFOS in seawater (Benskin et

243 al., 2012). Interlaboratory agreement (closer to 'accuracy') for PFCs in seawater were

244 generally within a factor of 2 (Benskin et al., 2012). Sampling of the more hydrophobic

245 POPs is more challenging (Muir and Lohmann, 2013), but similar precision can be 
246 achieved. For the purpose of this paper, we did not perform a statistical analysis of data,

247 as would be appropriate, e.g., for algorithmic detection of fronts from satellite data, etc.

248 Yet as evident from the Discussion and Figures, in most instances cross-frontal

249 concentration changes were steep enough that no statistical test was needed to identify

250 the location of the front.

\section{Spatial Distribution of Pollutants in Relation to Ocean Fronts}

Global distribution of pollutants is believed to be determined largely by two factors:

254 (1) atmospheric transport and (2) oceanic transport. Most studies to date focused on

255 atmospheric transport, whereas few focused on oceanic transport. The problem of

256 pollutant transport partitioning between atmosphere and ocean can be looked at from

257 different angles, e.g., from theoretical considerations or numerical simulations with

258 global coupled ocean-atmosphere circulation models. Yet one of the most promising

259 approaches is an exploratory analysis of long oceanic transects that might hold clues. In

260 this section we review published data obtained along such transects, looking for front

261 signals and linking them to physical fronts. Biological fronts (e.g., fronts in chlorophyll

262 field) must play an important role, which sometimes might rival the role played by

263 physical fronts. Yet the science of biological fronts is still in its infancy (e.g., Belkin and

264 O'Reilly, 2009), therefore here we focus on physical fronts in temperature, salinity and

265 density fields.

266 Our analysis is based on an intuitively obvious notion that atmospherically-

267 dominated surface distributions of pollutants are, at least initially, spatially smooth. The

268 inherent smoothness of atmospheric fields (compared with oceanic fields) stems mostly 
269 from the former's relatively large temporal variability. While bearing certain similarities

270 with oceanic fronts, the atmospheric fronts (Berry et al., 2011) lack stability: Their

271 spatio-temporal scales of variability and corresponding magnitudes are drastically

272 different from those of oceanic fronts. Therefore, the atmospheric fronts are much less

273 likely to leave a lasting imprint on the ocean. Most atmospheric fronts are relatively

274 short-lived (a few days or weeks), although some of them, e.g. the famous Mei-yu Front

275 in East Asia, may persist for up to a few months, and only a couple of fronts in the

276 Northern Hemisphere are semi-permanent, namely the Polar Front and Arctic Front,

277 while the Polar Front in the Southern Hemisphere is probably the only truly permanent

278 atmospheric front. Nonetheless, pollutants can be transported by various mechanisms,

279 including those linked to atmospheric fronts, e.g. cyclones traveling along these fronts.

280 Sometimes pollutants are transported across oceans as long filaments reminiscent of

281 fronts or as isolated blobs of air (Wilkening et al., 2000) similar to oceanic rings spawned

282 by fronts. The atmospheric fronts also play an important role in wet deposition of

283 pollutants. Indeed, up to $90 \%$ of rainfall in major storm-track bands is associated with

284 atmospheric fronts (Catto et al., 2012). The bulk of long-distance moisture transport is

285 carried by front-like atmospheric rivers (Newell et al., 1992; Rutz et al., 2014) linked to

286 heavy rainfalls (Lavers et al., 2011). Therefore, atmospheric rivers must be crucial to wet

287 deposition of pollutants. Each of the above features can leave a distinct event-like

288 signature in the surface layer of the ocean. Yet the inherently high variability of these

289 atmospheric features precludes their long-term impact on the ocean. It also means that

290 time-averaged atmospheric deposition of any substance onto the sea surface is bound to

291 be spatially smooth. Hence stepwise discontinuities in spatial distributions of pollutants 
292 along oceanic transects are likely linked to oceanic discontinuities, i.e. fronts. To prevent

293 contamination of our analysis by step-like features at the sea surface caused by transient

294 atmospheric phenomena, we emphasize the importance of repeat oceanographic transects

295 that allow the researcher to distinguish quasi-stationary features from transients. To date,

296 by far the most complete archive of pollutant measurements along repeat transects has

297 been assembled - and is appended annually - thanks to regular Antarctic voyages by RV

298 Polarstern. Even though there is no central repository of pollutant data, Polarstern data

299 are promptly reported in peer-reviewed journal papers accompanied by supplementary

300 materials that include data tables. The below analysis is mostly based on these data,

301 particularly those for perfluorinated alkyl acids and sulfonates. Owing to our reliance on

302 data reported from cruises by RV Polarstern, the emphasis is on fronts in the Eastern

303 Atlantic Ocean.

305 4. a) Canary Current Front

306 The Antarctic voyages of RV Polarstern follow the same pattern, departing from

307 Bremerhaven and having first stations occupied in the North Sea, English Channel or Bay

308 of Biscay. Here we focus on the northern segments of these tracks as the ship proceeds

309 from European coastal waters southward into much less polluted waters off NW Africa

310 and farther south into even less polluted waters of the Equatorial Atlantic (albeit elevated

311 concentrations of some banned POPs have been observed off West Africa (Gioia et al.,

312 2008b, 2011), possibly due to a combination of illegal waste dumping coupled to

313 atmospheric emissions). As we are about to see below, transitions between these waters

314 are not gradual. Instead, concentrations of individual pollutants decrease southward in a 
315 stepwise fashion as the ship crosses over sharp fronts associated with major oceanic

316 currents. These fronts act as water mass boundaries. While thermohaline signatures of

317 these fronts have been studied for decades, this is the first time that these fronts are

318 identified in distributions of pollutants.

319 During the 2007 voyage, RV Polarstern has crossed a sharp front between $38^{\circ} \mathrm{N}$ and $32036^{\circ} \mathrm{N}$, which manifests in north-south distributions of individual PFC concentrations 321 (Figure 3). For example, PFNxA and PFNA exhibit little variability from Sta.1 up to 322 Sta.10, where PFNxA drops 6-fold to St.11, while PFNA drops two-fold. These drastic 323 changes are collocated with the Azores Current (Front), which is known to extend zonally 324 along $34^{\circ}-35^{\circ} \mathrm{N}$ (Gould, 1985). Coincident with these sharp drops is the PFNpA 325 emergence at Sta.11, after which PFNpA remains fairly constant up to Sta. 20. This 326 location marks the point where the Canary Current veers offshore from the African coast 327 westward.

328 The sharp drops in PFC concentrations seem to contrast with the rather gradual 329 southward increase of SST along the ship track until $20^{\circ} \mathrm{N}$ (Ahrens et al., 2009), which 330 can be explained by the divergent nature of the NW African upwelling area, one of the 331 largest and most persistent eastern boundary upwelling regions in the World Ocean. This 332 phenomenon illustrates the profound difference between the largely divergent nature of 333 eastern boundaries and largely convergent nature of western boundaries. Indeed, the 334 western boundary regions feature convergences of cold and warm currents that create the 335 largest SST gradients in the World Ocean (e.g., Labrador Current and Gulf Stream; 336 Falkland/Malvinas Current and Brazil Current; Oyashio and Kuroshio). A study in 337 contrast, the mostly divergence-dominated environments along eastern boundaries of the 
338 Atlantic, Indian, and Pacific oceans are not conducive to forming exceptionally strong

339 SST fronts. Thus, the rather gradual north-south increase in SST along the Polarstern

340 track is not at all surprising.

341 Data from the 2008 voyage of RV Polarstern (Figure 4) reveal a different picture,

342 devoid of sharp fronts. It is hard to rationalize the drastic change of pattern. The most

343 obvious interpretation of this striking metamorphosis is temporal variability of either the

344 front itself, varying concentrations of PFCs upstream of the cruise track and/or trends

345 masked by varying sampling stations. Either way, this is a topic of a separate

346 investigation, which is well beyond the scope of this study.

347 There was no sampling of PFCs during the 2009 voyage. The PFC sampling resumed

348 during the 2010 voyage, when, again, sharp fronts, albeit at different locations (compared

349 with 2009), were observed (Figure 5). Two fronts stand out, the Canary Current Front

350 between Stas. $12-13\left(20^{\circ}-25^{\circ} \mathrm{N}\right)$ and South Equatorial Current Front between Stas. 19-20

$351\left(3^{\circ}-7^{\circ} \mathrm{S}\right)$. The best indicator of the Canary Current Front is PFOA: Its concentration drops

352 precipitously below MDL across this front. Concentrations of PFHxA and PFHpA also

353 drop across this front, albeit less abruptly. The best indicator of the South Equatorial

354 Front is PFHxA, whose concentration drops below MDL across this front.

355 Data collected by RV Polarstern in 2010 across the Canary Current Front are 356 consistent with observations in the 2007 cruse of RV Oden (Figure 6). All four PFCs

357 dropped precipitously across this front between Stas. 6-7 $\left(23.6^{\circ}-27.3^{\circ} \mathrm{N}\right)$, immediately

358 SW of the Canary Islands. In both cruises (Oden-2007 and Polarstern-2010) the front

359 was detected at approximately the same location south or southwest of the Canary Islands.

360 However, the PFOS signatures of this front observed in 2007 and 2010 were quite 
361 different: Whereas in 2007 the PFOS (alongside with PFOA) was an excellent tracer of

362 the front, in 2010 the PFOS concentrations have not changed across this front - unlike the

363 PFOA concentrations that fell below MDL across the front. Another prominent feature

364 along this section sampled by RV Oden in 2007 is the Rio de La Plata Plume in the SW

365 Atlantic revealed by maximum concentrations of all PFCs (especially PFOS and PFOA)

366 except for PFHpA.

367 Measurements of HCH from RV Polarstern in November 2008 (Xie et al., 2011b,

368 Fig. 1b therein) revealed the same sharp transition from polluted European waters to

369 relatively pristine waters off West Africa. In 2008, this sharp transition occurred in two

370 steps $\left(38^{\circ} \mathrm{N}-31^{\circ} \mathrm{N}\right.$ and $\left.25^{\circ} \mathrm{N}-16^{\circ} \mathrm{N}\right)$ (Xie et al., 2011b, Fig. $1 \mathrm{~b}$ and Table 3 therein), which

371 is consistent with the location of the same transition based on our measurements from RV

372 Oden in $2007\left(27^{\circ} \mathrm{N}-24^{\circ} \mathrm{N}\right)$ (Figure 6). Measurements of polycyclic aromatic

373 hydrocarbons (PAHs) in October 2005 along a similar north-south transect in the NE

374 Atlantic (Nizzetto et al., 2008, Fig. 1b therein) revealed a stepwise decline in dissolved

375 PAHs concentrations south of the Canary Islands, between $22^{\circ} \mathrm{N}$ and $17^{\circ} \mathrm{N}$, slightly south

376 of the front location in 2007 and 2008. Lakaschus et al. (2002) compiled measurements

377 of HCHs made from RV Polarstern between the North Sea and Antarctica in 1987, 1989,

378 1991, 1993, 1995, 1997, and 1999. These data consistently show a sharp decline in $\alpha$ -

$379 \mathrm{HCH}$ from the Portugal Current to the Canary Current (ibid., supporting info). The best

380 spatial resolution along this track was achieved in 1999, revealing a steep $\alpha-\mathrm{HCH}$ drop

381 (front) between $25^{\circ} \mathrm{N}$ and $20^{\circ} \mathrm{N}$ (ibid., Fig.3a). Taking together, these data show that

382 notwithstanding the manifold decrease in $\alpha-\mathrm{HCH}$ over the last decades, the contaminant's

383 spatial pattern remains fairly robust, featuring a sharp transition from European waters to 
384 the subtropical gyre. The temperature step of a few degrees across the Canary Front

385 cannot cause a noticeable change in $\mathrm{HCH}$ concentrations. Strong atmospheric deposition

386 of POPs can leave an oceanic imprint such as elevated aqueous PCB concentrations off

387 West Africa, likely from atmospheric emissions (including those from illegal waste

388 dumping of banned POPs) rather than ocean currents (Gioia et al., 2008b, 2011).

390 4. b) Gulf Stream Front

391 One of the strongest fronts of the World Ocean - the Gulf Stream Front - was sampled

392 during the 2009 cruise 464 of RV Endeavor, EN 464 (Figures 7-9). The cross-Gulf

393 Stream pattern revealed by Endeavor was quite peculiar. The warm (southern) front of

394 the Gulf Stream was not detected in SST, apparently because the SST signature of the

395 Gulf Stream is extremely weak in late July when summer heating all but obliterates

396 surface fronts. The salinity signature of the Gulf Stream was still noticeable (Benskin et

397 al., 2012b, supporting information, Table S9) although salinity data were rudimentary.

398 All four PFCs peaked as Endeavor left the Gulf Stream by crossing over the cold 399 (northern) front bounding the Gulf Stream between Sta. 29-30 $\left(37.3^{\circ}-38.2^{\circ} \mathrm{N}\right)$.

400 Concentrations of all four PFCs remained very high at Stas. $30-31\left(38.2^{\circ}-39.0^{\circ} \mathrm{N}\right)$,

401 decreased as Endeavor proceeded northward, and peaked over the New England Shelf, in 402 the proximity of Rhode Island Sound and Narragansett Bay.

403 Along the same RV Endeavor transect in 2009, samples were also taken for 404 hydrophobic organic compounds, including various organochlorine pesticides, PCBs, 405 PAHs and PBDEs. Results show that several pollutants are still predominantly land406 derived, i.e. those where on-going emissions from urban/industrial areas (manifested in 
407 enhanced concentrations in coastal regions) exceed concentrations in the open ocean.

408 Examples of these pollutants are PAHs, PBDEs, a-HCH and lindane with higher 409 concentrations in Rhode Island Sound, decreasing to concentrations below detection limit

410 in the open ocean ( $\underline{\text { Table 3 }}$ ). As noted above, there is only a small (with respect to 411 physico-chemical properties) temperature gradient (around $7 \mathrm{~K}$ ) between the Sargasso

412 Sea and Rhode Island Sound, so the sharp decrease in concentration of most pollutants is

413 due to removal (by particle settling, photolysis and biodegradation) and dilution, rather

414 than redistribution. For example, the dissolved concentration of a-HCH decreased

415 roughly 4-fold between the Gulf Stream and Rhode Island Sound, while the temperature

416 difference affects air-water partitioning by less than a factor of 2 (Table 3 ).

417 In contrast, the more persistent and already phased-out PCBs and HCB displayed 418 concentration distributions that suggest ocean fronts' importance in maintaining 419 concentration gradients (Figure 8): PCB 28 and HCB had higher concentrations in the 420 Gulf Stream (probably originating from the Gulf of Mexico) than in Rhode Island Sound.

421 The higher molecular weight PCBs 52, 101 and 118 displayed a distribution that shows a 422 decrease in concentrations between the Gulf Stream and Rhode Island Sound, possibly 423 due to sorption to particles in-between these two regions. For PCBs 28 and 52, the Gulf 424 Stream carried higher concentrations than the Sargasso Sea, while the opposite was true 425 for PCBs 101 and 118. Elevated concentrations of $\mathrm{HCB}$ and PCBs 28 and 52 could 426 originate from the Gulf of Mexico/Mississippi River. Taken together, the transect off the 427 U.S. Northeast showed the importance of the Gulf Stream with its associated fronts 428 coupled with the pollutant characteristics (dominated by primary or secondary emissions). 
429 The sampling was not detailed enough to find evidence of other fronts closer to shore

430 (mid-shelf front, shelf-slope front).

\section{4. c) River Plumes}

433 River plumes are notable features crossed by research vessels traversing the Atlantic

434 Ocean (Benskin et al., 2012b). Two outstanding river plumes in the western Atlantic 435 Ocean were crossed by RV Endeavor in 2009, namely the Amazon River and Rio de la 436 Plata plumes. We estimated the influence of the Amazon River and Rio de la Plata 437 plumes based on salinity differences for PFCs (Table 4). We applied a two-endmember 438 approach to estimate the source strength of the river plumes, assuming that any increase 439 of PFCs in the plume was solely due to the river outflow. The background (fully marine) 440 PFC concentration was subtracted, and the remaining difference normalized to the

441 freshwater fraction of the sample ( 442 river's plume.

443 In the case of the Amazon River plume, dissolved concentrations increased by up to

$44410 \mathrm{pg} \mathrm{L}^{-1}$ relative to the concentrations in fully marine waters, while salinity was at 27 445 psu (a dilution of seawater (36.4 psu in this region) by 26\%). As evident from Table 4 , 446 the four consecutive samples taken in the Amazon River plume revealed substantial 447 differences in concentrations (Benskin et al., 2012b). This most likely reflected the 448 heterogeneity of the plume. This subject is poorly studied, largely because it requires 449 high-resolution observations across a river plume and such data sets are extremely rare. 450 Another reason is the plume scale. Small plumes naturally tend to be more uniform than 451 large plumes created by such rivers as the Amazon River. The Amazon (freshwater) 
452 plume that we sampled several hundred $\mathrm{km}$ offshore contributed an additional tens-to-

453 hundreds pg L ${ }^{-1}$ of the various PFCs towards the Atlantic Ocean (Figure 7). The average

454 discharge of the Amazon River is ca. $1.6 \times 10^{5} \mathrm{~m}^{3} \mathrm{sec}^{-1}$ or $5 \times 10^{12} \mathrm{~m}^{3} \mathrm{yr}^{-1}$ (Salisbury et

455 al., 2011). Consequently, ca. $1.4 \mathrm{t}$ of PFCs are flushed annually into the open Atlantic

456 Ocean (Table 4).

457 Waters affected by the Rio de la Plata plume were sampled during the RV Oden

458 cruise in 2007 at two stations (Benskin et al., 2012b), as evidenced by decreases in

459 salinity in samples 24 and 25 (by 2 psu), coupled to a marked increase in PFCs (Figure

460 6). Concentrations of sum PFCs increased from $\sim 100 \mathrm{pg} / \mathrm{L}$ outside the plume to $350-$

$461540 \mathrm{pg} / \mathrm{L}$ in the plume. The dominant PFCs were PFOS, which increased 4-fold to 140 -

$462170 \mathrm{pg} / \mathrm{L}$ in the plume, and PFOA, which increased at least 10 -fold to $100 \mathrm{pg} / \mathrm{L}$ in the

463 plume. Other notable PFCs were PFUnA, which reached $90 \mathrm{pg} / \mathrm{L}$ in the plume, and

464 PFHxA, which increased three- to tenfold in the plume (

465 The average discharge of the Rio de la Plata is ca. $2.2 \times 10^{4} \mathrm{~m}^{3} \mathrm{sec}^{-1}$ or $7 \times 10^{11} \mathrm{~m}^{3}$

$466 \mathrm{yr}^{-1}$ (Framiñan and Brown, 1996). Combining the increase attributed to the freshwater

467 with the river's annual discharge results in an annual delivery of $3.5 \mathrm{t}$ of PFCs from the

468 Rio de la Plata into the South Atlantic Ocean (able 4). The striking differences between

469 the Amazon River vs. Rio de la Plata discharges of PFCs likely reflect profound 470 differences in demographics and economic geography of their respective watersheds.

471 Indeed, the Amazon River Basin is populated by just about 5 million people spread over

4727 million $\mathrm{km}^{2}$. A study in contrast, the Rio de la Plata drains the Buenos-Aires

473 megalopolis, with 14 million people and most of Argentina's industrial capacity 
474 (Colombo et al., 2011), and the Montevideo agglomeration (Uruguay) with 2 million 475 people.

476 To put the total mass of PFCs delivered to the Atlantic into perspective, we 477 calculated the outflow of PFCs from Narragansett Bay, where concentrations of PFCs is 478 very high (5.8 ng/L, after Benskin et al., 2012b). Yet long-term average annual 479 freshwater discharge of the Bay is only $107.5 \mathrm{~m}^{3} / \mathrm{s}$ (or $3.4 \times 10^{9} \mathrm{~m}^{3} / \mathrm{yr}$ ) (Ries, 1990), 480 resulting in an average annual delivery of total PFCs of ca. $77 \mathrm{~kg} / \mathrm{yr}$. This amount pales in 481 comparison with the amounts of PFCs discharged by the Amazon River and Rio de la 482 Plata.

483 The same RV Endeavor transect in 2009, which reported PFC concentrations across 484 the Amazon River plume, has also reported PCBs, pesticides, PAHs and PBDEs 485 (Lohmann et al., 2012, 2013a, 2013b). In most cases, no significant change in 486 concentrations was found. Concentrations of PCBs increased slightly across the Amazon 487 plume (Figure 9) , but the scatter in PCB concentrations is clearly elevated relative to that 488 in PFCs, making it difficult to draw firm conclusions.

489 On a more general note, river plumes have the potential to be important pathways 490 into the oceans for water-soluble and persistent compounds ( $\mathrm{Li}$ and Daler, 2004) beyond 491 PFCs, such as herbicides (Alegria and Shaw, 1999), pharmaceuticals (Zhang et al., 2012) 492 and personal care products (Qi et al., 2014). For example, the more recalcitrant artificial 493 sweetener sucralose has been detected in part of the Gulf Stream already (Mead et al., 494 2009). 
497

498

499

500

501

502

503

504 from polluted European waters to the relatively pristine trade winds zone could be

505 observed on a transect from the Bay of Biscay to southern Argentina. North of the front

506 (which is linked to the Canary Current), concentrations of PFOA, PFOS and PFBS were

$507>100 \mathrm{pg} / \mathrm{L}$, decreasing to $<50 \mathrm{pg} / \mathrm{L}$ (and below detection limit for PFBS) south of the

508 front. The same transition across the Canary Current was observed for hydrophobic

509 organic pollutants, such as hexachlorocyclohexanes and even polycyclic aromatic

510 hydrocarbons. More complex pollutant patterns were observed between the Gulf Stream

511 and Rhode Island Sound. The more persistent polychlorinated biphenyls and

512 hexachlorobenzene actually displayed higher concentrations in the Gulf Stream than in

513 the Sargasso Sea or Rhode Island Sound. In contrast, the emerging perfluorinated

514 compounds displayed a strong increase from the Gulf Stream towards Rhode Island

515 Sound. The sampling campaigns we re-evaluated were not detailed enough to assess the

516 effect of mid-shelf and shelf-break fronts on pollutant dynamics, though the possibility of

517 detecting perfluorinated compounds in one liter samples opens the door to a much more

518 detailed understanding of the interplay between fronts and organic pollutant dynamics in

519 the oceans. 
524 POPs and fronts has been stimulated by participation in the SETAC Asia Pacific 2010

5245 POPs and fronts has been stimulated by participation in the SETAC Asia Pacific 2010

525 Conference in Guangzhou; the travel support of the South China Sea Institute of

526 Oceanology, Chinese Academy of Sciences, is greatly appreciated. 